DOI: $\underline{10.17805 / g g z .2019 .6 .3}$

\title{
У. Шекспир и К. Марло в индивидуальных тезаурусах (на материале русскоязычных дневников XIX-XXI вв.)
}

\author{
Б. Н. Гайдин
}

\author{
Московский гуманитарный университет
}

В статье проанализированы различные контексты упоминания английских драматургов У. Шекспира и К. Марло, а также их произведений в русскоязычных дневниках XIX-XXI вв., опубликованных в рамках проекта «Прожито». Число упоминаний Шекспира и его пьес в тезаурусе русской культуры в силу укоренившегося «культа Шекспира» значительно превыпает число отсылок к наследию его современников. Полученные данные позволяют выделить некоторые тенденции, связанные с рецепцией двух английских драматургов в индивидуальных тезаурусах. Если охватить даже $10 \%$ представленных случаев отсылок к Шекспиру в русскоязычных дневниках в рамках одной статьи едва ли возможно, то представить примеры, связанные с его современником Марло, вполне под силу из-за их сравнительной малочисленности.

Ключевые слова: У. Шекспир; К. Марло; современники Шекспира; Шекспир в русской культуре; Марло в русской культуре; дневники; тезаурусный подход; тезаурусный анализ; индивидуальные тезаурусы; "Прожито»; русская культура

\section{W. Shakespeare and C. Marlowe in Individual Thesauri (The Case of Russian-language Diaries of the 19th-20th Centuries)}

B. N. Gaydin

Moscow University for the Humanities

The author analyzes different contexts of mentions of the English playwrights W. Shakespeare and C. Marlowe as well as of their works in some Russian-language diaries written in the 19th-20th centuries that have been published within the framework of the "Prozhito" project. The number of references to

\footnotetext{
* Статья подготовлена в рамках проекта «Кристофер Марло и его творчество в русской и мировой культуре: междисциплинарный взгляд» при финансовой поддержке Российского фонда фундаментальных исследований (грант № 18-012-00679).

The article was prepared within the framework of the project "Christopher Marlowe and His Literary Heritage in Russian and World Culture: An Interdisciplinary Look" with financial support from the Russian Foundation for Basic Research (grant No. 18-012-00679).
} 
Shakespeare and his plays in the thesaurus of Russian culture far exceeds the number of mentions of his contemporaries' legacy due to the "cult of Shakespeare". The obtained data gives us an opportunity to reveal some tendencies related to the reception of the two English dramatists in individual thesauri. If it is almost impossible to cover even 10 percent of the available cases of references to Shakespeare in Russophone diaries in one article then it is feasible to present examples connected with his contemporary, Marlowe, because of their comparative paucity.

Keywords: W. Shakespeare; C. Marlowe; Shakespeare's contemporaries; Shakespeare in Russian culture; Marlowe in Russian culture; diaries; thesaurus approach; thesaurus analysis; individual thesauri; "Prozhito"; Russian culture

\section{ВВЕДЕНИЕ}

Литературные сочинения, письма, воспоминания, дневниковые записи и т. д. большого числа русскоязычных авторов XVIII-XXI вв. полны примерами влияния У. Шекспира. Для большинства художественных произведений, относящихся к этому числу, характерна шекспиризация, т. е. подражание образцам, освоение и переосмысление шекспировских тематизмов, сюжетов, мотивов, образов и т. д., иными словами, поэтики британского поэта и драматурга. Образцов же воплощения шекспиризма, который предполагает конгениальное развитие шекспировской традиции (масштабная картина мира, использование схожих стратегий художественного мышления и т. д.), не так много (см, например: Луков, Захаров, 2008; Захаров, 2008) ${ }^{1}$. Обнаружить примеры шекспиризма значительно сложнее, поскольку там могут отсутствовать явные отсылки к Шекспиру. Современные информационные технологии здесь пока едва ли могут сильно помочь исследователям.

Однако, с нашей точки зрения, интерес представляют не только произведения и работы известных авторов, режиссеров, актеров и т. д., в которых можно обнаружить «шекспировский след». Особое значение для более глубокого понимания специфики рецепции Шекспира в современной культуре и ее трансформаций в различные исторические периоды нашей страны приобретают примеры из творчества малоизвестных авторов. Основная их часть не имеет большой художественной ценности, однако именно на этом широком эмпирическом материале можно выявить основные тенденции в рецепции и апроприации шекспировского наследия в массовой культуре. Бурное разви-

\footnotetext{
${ }^{1}$ На наш взгляд, ярким образцом не только шекспиризации, но шекспиризма являются, к примеру, романы и новеллы Ю. О. Домбровского. Проанализировав их, мы пришли к гипотезе, что глубокое понимание советским писателем хода развития истории и роли художника в нем во многом схоже с тем, которое мы можем подчерпнуть из шекспировских пьес, поэм и сонетов. См.: Гайдин, 2018.
} 
тие интернет-коммуникации в России в 2000-2010-х гг. существенно увеличило число доступных для изучения примеров. Также перспективным представляется изучение т. н. «частных / приватных Шекспиров» ${ }^{2}$ в различных (особенно малодоступных) личных дневниках носителей русской и других национальных культур. Не меньший интерес представляют и упоминания других шекспировских современников в подобных частных тезаурусах.

\section{У. ШЕКСПИР И К. МАРЛО В ЛИЧНЫХ ДНЕВНИКАХ, ОПУБЛИКОВАННЫХ В ЭЛЕКТРОННОМ КОРПУСЕ «ПРОЖИТО»}

Одной из самых больших и стремительно развивающихся в русскоязычном сегменте Интернета баз данных, содержащих оцифрованные версии частных дневников, является проект «Прожито» (https://prozhito.org/). Приведем результаты по запросам «Шекспир» и «Марло» и рассмотрим несколько примеров. Результаты таковы:

- Шекспир — 1186 записей (1806-2017 гг.) (<Результаты по ключевому слову «Шекспир»>, б/д: Электронный ресурс);

- Марло - 5 записей $(1934,1953,1957,1963$; <Результаты по ключевому слову «Марло»>, б/д: Электронный ресурс); к указанным пяти записям можно добавить еще две, которые можно найти по ключевому слову «Марлоу» (1980, 1982; <Результаты по ключевому слову «Марлоу»>, б/д: Электронный ресурс $)^{3}$.

Конечно, неудивительно, что количество упоминаний Шекспира гораздо больше, чем отсылок к Марло. Охватить все 1186 записей едва ли возможно даже в рамках коллективной монографии (поэтому мы ограничимся только самой первой и самой последней из имеющихся в базе данных на данный момент), а вот проанализировать случаи отсылок к английскому дра-

\footnotetext{
${ }^{2}$ Выражаем благодарность В. С. Макарову за указание на существование этого термина. См. примеры употребления словосочетания "private Shakespeare(s)", которое используется для обозначения фактов личной жизни драматурга, конкретных случаев интерпретаций его наследия разными людьми (например, домашние постановки шекспировских пьес) и даже в значении «рядовой Шекспир» (рядовой Чарли Шекспир - герой фильма «На страже смерти» (“Deathwatch”, 2002), снятого режиссером М. Дж. Бассеттом (Michael J. Bassett)): Goodman, 1997; Honigmann, 1998; Sawyer, 2003: 15; Ocampo-Guzman, 2006; Pogue, 2006: 145; Dobson, 2011; Rasmus, 2016: Электронный pecypc; Deathwatch (2002), s.d.: Электронный ресурс; и др.

${ }^{3}$ Два результата не связаны с драматургом К. Марло: 1) В записи инженер-конструктора К. С. Попова от 14 февраля 1930 г. упоминается актер Джон Марлоу (John Marlowe), который сыграл главную роль в фильме «Ночной крик» (см.: Попов, б/д: Электронный ресурс). 2) Актер О. И. Даль в заметке от 3 апреля 1975 г. пишет о постановке шекспировской «Двенадцатой ночи» (реж. Питер Джеймс / Peter James), в которой он сыграл роль сэра Эндрю Эгьючика, однако, упоминая Марлоу, имеет ввиду главного героя Чарльза Марлоу (Charles Marlow) пьесы «Ночь ошибок, или Унижение паче гордости» (She Stoops to Conquer) Оливера Голдсмита (Oliver Goldsmith). См.: Даль, б/д: Электронный ресурс.
} 
матургу Марло на «Прожито» можно в полном объеме. Это, на наш взгляд, представляет интересный материал для лучшего понимания места английского поэта и драматурга Марло в современной русской культуре.

Первое упоминание Шекспира в загруженных дневниках - заметка Василия Андреевича Жуковского, сделанная в 1806 г., где он размышляет о том, в каком порядке лучше знакомиться с творчеством различных авторов, чтобы глубже их понимать путем сравнения. По его мнению, изучать драматургию Шиллера-трагика лучше вместе с сочинениями Шекспира: «Читать стихотворцев, не каждого особенно, но всех одинакового рода вместе; частный характер каждого сделается ощутительнее от сравнения. Например, Шиллера как стихотворца в роде баллад читать вместе с Бюргером, как стихотворца философического вместе с Гёте и другими; как трагика вместе с Шекспиром» (Жуковский, б/д: Электронный ресурс) ${ }^{4}$. Известно, что хотя «в собственном художественном творчестве Жуковского шекспировский гений отразился практически незаметно» (Захаров, 2010: 104), однако определенное влияние на его поэтическое мировоззрение Шекспир, безусловно, имел, несмотря на то, что некоторые моменты в творчестве драматурга вызывали у русского поэта определенные возражения (см., например: Лебедева, Янушкевич, 2016: 654).

Последнее же упоминание принадлежит певице, художнице, поэтессе Галине Г. Ларской, которая цитирует в своей дневниковой записи от 23 апреля 2017 г., т. е. в день, когда принято отмечать день рождения и смерти У. Шекспира, два стихотворения. Одно написано Ларисой Морозовой (Цырлиной) и отсылает к самому британскому драматургу и его творчеству:

Дурачиться, от нежности спасаясь -

Ещё Шекспиру ведомый приём.

О, как же уязвима эта завязь

Любви, которой мы не признаём!

Второе же принадлежит Галине Гольд и пронизано гамлетовскими мотивами («отзвуками “Гамлета"...»):

Не пей вина, Гертруда - не поможет...

Да и потом, плохие нынче вина.

Взгляни, вокруг - содружество ничтожеств,

Среди которых ты - почти невинна.

\footnotetext{
${ }^{4}$ Впервые опубликовано: Шевырёв, 1853: 68-69. См. также: Жуковский, 2004: 36.
} 
Прогнило все, и ложь, как хлыст по спинам.

Кто против зла - безумен и виновен.

Как уберечь в таком вертепе сына,

Где жажда власти, как желанье крови?

Виват тому, кто в бой вступил неравный,

Кто смел и честен, но не слишком свят,

Кто одинок, не понят, не оправдан.

Всегда рапиры избранных разят...

(цит. по: Ларская, б/д: Электронный ресурс) ${ }^{5}$

Теперь обратимся к анализу отсылок к К. Марло.

Итак, на момент написания данной статьи первая запись в корпусе дневников, в которой упомянут английский литератор, датируется 23-26 октября 1934 г. и принадлежит поэту и переводчику Михаилу Алексеевичу Кузмину. В ней он выражает свое отношение к творчеству французского композитора Клода Дебюсси: «Я упиваюсь Дебюсси, не только как прекрасным искусством, но и как регулирующим и стимулирующим средством. $<\ldots>$ Листва, влага, колокола, луна, снег, море, лето и поэзия, французская поэзия, поскольку она кельтическая и хрупкая, с античными и итальянскими реминисценциями, как сонеты Шекспира, как лирика Грина и Марло, как, в принципе, прерафаэлиты и Д’Аннунцио. <...> Он мне не вернул поэзию, а как-то прочистил уши и сердце к ней, причём открылись с небывалой необыкновенностью и <не > только те, на кого он писал музыку, но и Шекспир, и Данте, и Пушкин» (Кузмин, б/д: Электронный ресурс) ${ }^{6}$. Как видим, в тезаурус Кузмина входило творчество не только Шекспира, но и поэзия, как минимум еще двух его современников: Роберта Грина и Кристофера Марло, которых принято относить к кругу т. н. «университетских умов» (см., например: Дживелегов, 1943; Луков, 2010-: Электронный ресурс; Roy, 2019).

Второй пример - эссе советского писателя, поэта и переводчика Эммануила Генриховича Казакевича «Метающий копье: опыт литературной характеристики В. Шекспира», датируемое 1 января 1953 г. В нем он поднимает «шекспировский вопрос», выражая уверенность, что «Шекспир - имя собирательное, как Гомер. Произведения его — очень своеобразный народный английский эпос XVI века, последний великий, - м. б., самый великий эпос в мировой словесности» (Казакевич, б/д: Электронный ресурс). Вспоминая известное выражение Р. Грина из памфлета «На грош ума» о том, что Шекс-

\footnotetext{
${ }^{5}$ См. также: Морозова (Цырлина), 2010: Электронный ресурс; Гольд, 2017: Электронный pecypc.

${ }^{6}$ См. также: Кузмин, 1998: 128.
} 
пир был «вороной, рядящейся в чужие павлиньи перья», Казакевич приходит к выводу, что «человек из Стратфорда» был «помрежем», который занимался хранением, переписыванием и сводом чужих текстов. Наконец, по его мнению, «именуемый произведениями Шекспира эпос настолько же выше Марло и др., насколько Гомер выше Пиндара, Алкея и прочих реально существовавших поэтов. С др[угой] стороны, преимущество Марло и др[угих] реально существовавших поэтов перед Шекспиром, как и Пиндара и др[угих] перед Гомером, заключается в том, что они реально существовали и их труд и подвиг является ${ }^{7}$ их личным трудом и подвигом. Оценивая их творчество, не следует их сравнивать с Шекспиром - это несравнимые величины» (там же). Таким образом, мы опять встречаем пример преклонения перед «Бардом» (в данном случае коллективным проектом) и некоторого уничижительного отношения к другим его современникам.

Третий пример - дневниковая запись аргентинского писателя Адольфо Биоя Касареса от 26 июня 1957 г. ${ }^{8}$ В ней он вспоминает свой разговор с Х. Л. Борхесом, который, прочитав поэму «Геро и Леандр», пришел к мнению, что Марло был нетрадиционной сексуальной ориентации, поскольку более страстно описывает героя, чем героиню. Касарес соглашается с мнением друга, резюмируя: «Марло был гомосексуалистом сверх меры, как, видимо, многие во времена Шекспира» (Биой Касарес, б/д: Электронный ресурс).

Четвертый пример - литературовед Ромэн Гафанович Назиров в записи от 6 декабря 1957 г. отметил, что зритель неохотно идет на «серьезные пьесы» и среди прочих «финансовых неудач» театрального сезона 1955-1956 гг. на Бродвее называет «Тамерлана Великого» Марло (Назиров, б/д: Электронный ресурс). Речь идет о «мелодраме в двух частях» режиссера Уильяма Тайрона Гатри (William Tyrone Guthrie), которая шла в Нью-Йорке на сцене Winter Garden Theatre c 19 января по 4 февраля 1956 г. (Tamburlaine the Great ... , s.d.: Электронный ресурс). Состоялись всего 20 показов, но она вошла в историю, как первая постановка пьесы Марло в Северной Америке. В ней играли актеры труппы Стратфордского шекспировского фестиваля (Stratford Shakespeare Festival Company, Канада; см., например: Callwood, 1956: 10).

Пятый пример - запись ленинградской поэтессы и прозаика Елены Андреевны Шварц, датируемая 8 сентября 1963 г., в которой она размышляет об «отринутом ангеле» Люцифере и образе Фауста, который «вырывается из предначертанного и этим велик». Она также отмечает, что Гёте не мог не быть знаком с пьесой Марло («его “Фауст” — слияние народного и Марло»),

\footnotetext{
${ }^{7}$ Так в оригинале.

${ }^{8}$ Хотя это перевод дневника, мы решили его также рассмотреть, поскольку переводы также можно считать частью тезауруса той или иной национальной культуры. См.: Луков В., Луков Вл., 2008, 2013.
} 
а Дьявол у английского драматурга «плачется по раю». Небольшая заметка заканчивается указанием автора на желание поставить «Фауста» (Шварц, б/д: Электронный ресурс).

Шестой пример - известный физик-теоретик, диссидент и общественный деятель Андрей Дмитриевич Сахаров в своей записи 6-7 февраля 1980 г. среди прочего написал: «Вечером второй раз был Феликс. Много рассказывал о гипотезе, что Марлоу — автор Шексп[ировских $]^{9}$ пьес» (Сахаров, б/д: Электронный ресурс $)^{10}$. Скорее всего, имеется ввиду Феликс Петрович Красавин, которому одному из немногих друзей было разрешено посещать академика Сахарова в Горьком (см.: Сахаров, 1996: 789). Можно предположить, что его интерес к этому вопросу был как-то связан с тем, что он, будучи в лагере, принял католицизм (см.: Сахаров, Боннэр, 2006: 55).

Наконец, седьмой пример - запись студента ГИТИСа Николая Яковлевича Троицкого от 21 декабря 1982 г., в которой он рассказывает о своих литературных предпочтениях, демонстрируя достаточно широкие познания в истории литературы. Среди прочих эпох он выделяет и интересующий нас период: «Неплохо знаю Елизаветинскую эру — вокруг Шекспира, хотя надо бы еще лучше изучить его современников, и тех, кого немного читал - Марлоу, Джонсона (блистательный поэт!), Уэбстера, Флетчера с Бомонтом. И тех, кого не читал - Лили, Грина, Кидда, Чепмена, Форда и т. п. Это о драматургах. А поэзию знаю слабо - чуток Спенсера, лучше Донна, да и всё, пожалуй» (Троицкий, б/д: Электронный ресурс) ${ }^{11}$. Таким образом, можно констатировать, что произведения К. Марло были известны определенному кругу студентов в СССР, скорее всего, благодаря выходу русскоязычного собрания сочинений Марло в 1961 г. (Марло, 1961).

\section{ЗАКЛЮЧЕНИЕ}

Приведенные примеры влияния У. Шекспира и К. Марло на культуру России, на наш взгляд, показывают, что в настоящее время носители русской культуры, несмотря на неоднозначные социокультурные тенденции, происходящие в недрах общества, по-прежнему способны к переработке и переосмыслению различных национальных и глобальных феноменов. Определенный интерес представляет и изучение влияния других старших и младших современников Шекспира на отечественную и мировую культуру. Поиск и анализ отсылок к ним в личных дневниках, воспоминаниях, письмах и т. д. могут дать новые сведения, которые позволят лучше, на наш взгляд, понять процессы, происходящие в настоящее время, если сравнить специфику по-

\footnotetext{
${ }^{9}$ Так в оригинале.

${ }^{10}$ См. также: Сахаров, Боннэр, 2006: 55.

${ }^{11}$ См. также: Троицкий, 2018: Электронный ресурс.
} 
нимания культурных феноменов в разные исторические эпохи, в которых можно обнаружить «след» Шекспира и его современников. Если влияние Шекспира на индивидуальные тезаурусы сложно проанализировать комплексно ввиду многочисленности релевантных примеров, то особенности рецепции наследия его современников в русскоязычных дневниках и письмах можно попытаться на данном этапе выявить с большей полнотой.

Перспективным представляется создание в будущем базы данных упоминаний Шекспира и его современников с возможностью визуализации и анализа имеющейся информации и различных связей между объектами и субъектами для лучшего понимания развития литературного и культурноисторического процессов в России и мире (см., например: У. Шекспир, его произведения и герои на карте России, б/д: Электронный ресурс). Как писал Ф. М. Достоевский, «чем более человек способен откликаться на историческое и общечеловеческое, тем шире его природа, тем богаче его жизнь и тем способнее такой человек к прогрессу и развитию» (Достоевский, 1978: 99). Можно вспомнить и другую мысль русского писателя о том, что «частный человек не может угадать вполне вечного, всеобщего идеала, - будь он сам Шекспир, - а следственно, не может предписывать ни путей, ни цели искусству» (там же: 102; курсив источника. - Б. Г.). Однако, с нашей точки зрения, с развитием информационных технологий именно анализ частных мнений о том или ином феномене способен дать новые данные для размышлений о нашем прошлом, настоящем и будущем.

Цифровая гуманитаристика, несмотря на множество проблем и критику, продолжает и должна развиваться!

\section{СПИСОК ЛИТЕРАТУРЫ}

Биой Касарес, А. (б/д) <Запись дневника А. Биоя Касареса от 26 июня 1957 г.> [Электронный ресурс] // Прожито. URL: https://prozhito.org/note/ 259615 (дата обращения: 15.11.2019).

Гайдин, Б. Н. (2018) У. Шекспир в тезаурусе Ю. О. Домбровского [Электронный ресурс] // Горизонты гуманитарного знания. № 4. С. 27-58. URL: http://journals.mosgu.ru/ggz/article/view/845 (дата обращения: 19.09. 2019). DOI: $10.17805 / g g z .2018 .4 .3$

Гольд, Г. (2017) Не пей вина, Гертруда [Электронный ресурс] // Стихи.ру. 7 февраля. URL: https://www.stihi.ru/2017/02/07/3599 [архивировано в WaybackMachine] (дата обращения: 15.11.2019).

Даль, О. И. (б/д) И пошло, и поехало... : <Запись дневника О. И. Даля от 3 апреля 1975 г.> [Электронный ресурс] // Прожито. URL: https:// prozhito.org/note/223603 (дата обращения: 15.11.2019). 
Дживелегов, А. К. (1943) «Университетские умы» // История английской литературы : в 3 т. М. ; Л. : Изд-во Академии наук СССР. Т. 1. Вып. 1. С. 341-361.

Достоевский, Ф. М. (1978) Г-н -бов и вопрос об искусстве // Достоевский Ф. М. Полн. собр. соч. : в 30 т. Л. : Наука, Ленинградское отделение. Т. 18: Статьи и заметки. 1845-1861. 371 с. С. 70-103.

Жуковский, В. А. (2004) Журнал, [1805-1806] // Жуковский В. А. Полн. собр. соч. и писем : в 20 т. М. : Языки славянской культуры. Т. 13: Дневники. Письма-дневники. Записные книжки. 1804-1833 гг. / сост. и ред. О. Б. Лебедева, А. С. Янушкевич. 608 с. С. 13-37.

Жуковский, В. А. (б/д) <Запись дневника В. А. Жуковского от 1806 г.> [Электронный ресурс] // Прожито. URL: https://prozhito.org/note/180718 (дата обращения: 15.11.2019).

Захаров, Н. В. (2008) Шекспиризм русской классической литературы: тезаурусный анализ / отв. ред. Вл. А. Луков ; Моск. гуманит. ун-т. Ин-т фундамент. и прикл. исследований ; Межд. акад. наук (IAS). М. : Изд-во Моск. гуманит. ун-та. 320 с.

Захаров, Н. В. (2010) Рецепция Шекспира в творчестве Жуковского // Знание. Понимание. Умение. № 1. С. 104-108.

Казакевич, Э. Г. (б/д) Метающий копье: опыт литературной характеристики В. Шекспира : <Запись дневника Э. Г. Казакевича от 1 января 1953 г.> [Электронный ресурс] // Прожито. URL: https://prozhito.org/note/245811 (дата обращения: 15.11.2019).

Кузмин, М. А. (1998) Дневник 1934 года / сост., подгот. текста, вступ. ст,. комм. Г. А. Морева. СПб. : Изд-во Ивана Лимбаха. 416 с.

Кузмин, М. А. (б/д) <Запись дневника М. А. Кузмина от 23-26 октября 1934 г.> [Электронный ресурс] // Прожито. URL: https://prozhito.org/note/ $\underline{545148}$ (дата обращения: 15.11.2019).

Ларская, Г. Г. (б/д) <Запись дневника Г. Г. Ларской от 23 апреля 2017 г.> [Электронный ресурс] // Прожито. URL: https://prozhito.org/note/365012 (дата обращения: 15.11.2019).

Лебедева, О. Б., Янушкевич, А. С. (2016) Отрывки из писем о Саксонии (примечания) // Жуковский В. А. Полн. собр. соч. и писем : в 20 т. М. : Изд. дом «ЯСК». Т. 11 (первый полутом): Проза 1810-1840-х годов / ред. А. С. Янушкевич. 1048 с. С. 649-657.

Луков, В. А., Луков, Вл. А. (2008) Тезаурусы: субъектная организация гуманитарного знания. М. : Изд-во Нац. ин-та бизнеса. 784 с.

Луков, В. А., Луков, Вл. А. (2013) Тезаурусы II: тезаурусный подход к пониманию человека и его мира. М.: Изд-во Нац. ин-та бизнеса. 640 с. 
Луков, Вл. А. (2010-) Английская ренессансная драматургия «университетских умов» - предшественников Шекспира [Электронный ресурс] // Энциклопедия «Мир Шекспира». URL: http://world-shake.ru/ru/Encyclopaedia/ 4136.html [архивировано в WaybackMachine] (дата обращения: 15.11.2019).

Луков, Вл. А., Захаров, Н. В. (2008) Шекспиризация и шекспиризм // Знание. Понимание. Умение. № 3. С. 253-256.

Марло, К. (1961) Соч. М. : Гос. изд-во худож. лит-ры. 662 с.

Морозова (Цырлина), Л. (2010) Дурачиться, от нежности спасаясь [Электронный ресурс] // Стихи.py. 16 июня. URL: https://www.stihi.ru/2010/ 06/16/553 [архивировано в WaybackMachine] (дата обращения: 15.11.2019).

Назиров, Р. Г. (б/д) <Запись дневника Р. Г. Назирова от 6 декабря 1957 г.> [Электронный ресурс] // Прожито. URL: https://prozhito.org/note/182195 (дата обращения: 15.11.2019).

Попов, К. С. (б/д) <Запись дневника К. С. Попова от 14 февраля 1930 г.> [Электронный ресурс] // Прожито. URL: https://prozhito.org/note/312307 (дата обращения: 15.11.2019).

$<$ Результаты по ключевому слову «Марло»> (б/д) [Электронный ресурс] // Прожито. URL: https://prozhito.org/notes?keywords=["Марло"] (дата обращения: 15.11.2019).

$<$ Результаты по ключевому слову «Марлоу»> (б/д) [Электронный ресурс] // Прожито. URL: https://prozhito.org/notes?keywords=["Марлоу"] (дата обращения: 15.11.2019).

$<$ Результаты по ключевому слову «Шекспир»> (б/д) [Электронный ресурс] // Прожито. URL: https://prozhito.org/notes?keywords=["Шекспир"] (дата обращения: 15.11.2019).

Сахаров, А. Д. (1996) Воспоминания : в 2 т. / ред.-сост. Е. Холмогорова, Ю. Шиханович. М. : Права человека. Т. 1.912 с. С. 789.

Сахаров, А. Д. (б/д) <Запись дневника А. Д. Сахарова 6-7 февраля 1980 г.> [Электронный ресурс] // Прожито. URL: https://prozhito.org/note/430982 (дата обращения: 15.11.2019).

Сахаров, А. Д., Боннэр, Е. Г. (2006) Дневники. Роман-документ : в 3 т. М. : Время. Т. 2. 864 с.

Троицкий, Н. Я. (2018) Дневник. Глава 4. Читательский пир духа [Электронный pecypc] // Николай Троицкий - ЖЖ. 13 декабря. URL: https://nicolaitroitsky.livejournal.com/8231100.html [архивировано в Wayback Machine] (дата обращения: 15.11.2019).

Троицкий, Н. Я. (б/д) <Запись дневника Н. Я. Троицкого от 21 декабря 1982 г.> [Электронный ресурс] // Прожито. URL: https://prozhito.org/note/ 128624 (дата обращения: 15.11.2019). 
У. Шекспир, его произведения и герои на карте России [Электронный ресурс] // Информационно-исследовательская база данных «Русский Шекспир». URL: http://rus-shake.ru/menu/Shakespeare-map/ (дата обращения: 15.11. 2019).

Шварц, Е. А. (б/д) <Запись дневника Е. А. Шварц от 8 сентября 1963 г.> [Электронный ресурс] // Прожито. URL: https://prozhito.org/note/105121 (дата обращения: 15.11.2019).

Шевырёв, С. П. (1853) О значении Жуковского в русской жизни и поэзии : речь, произнесенная в торжественном собрании Московского университета ординарным профессором русской словесности Степаном Шевырёвым 12 января 1853 г. М. : Унив. тип. [4], 84, 16, 25 с.

Callwood, J. (1956) How Stratford went to Broadway [Электронный pecypc] // MacLean's Magazine. March 3. P. 8-11, 50-53. URL: https://archive.macleans.ca/article/1956/3/3/how-stratford-went-to-broadway [архивировано в WaybackMachine] (дата обращения: 15.11.2019).

Deathwatch (2002) (s.d.) [Электронный pecypc] // Rotten Tomatoes. URL: https://www.rottentomatoes.com/m/deathwatch [архивировано в WaybackMachine] (дата обращения: 15.11.2019).

Dobson, M. (2011) Shakespeare in private: Domestic performance // Dobson M. Shakespeare and amateur performance: A cultural history. Cambridge ; N. Y. : Cambridge University Press. xiii, 265 p. P. 22-64. DOI: 10.1017/CBO9780511 $\underline{801259.002}$

Goodman, A. (1997) Virtuous philosopher and chameleon poet: The Shakespeare of Samuel Johnson and John Keats : Diss. Stanford, CA : Stanford University. viii, 236 leaves.

Honigmann, E. A. J. (1998) Introduction: Myriad-minded Shakespeare and the modern reader // Honigmann E. A. J. Myriad-minded Shakespeare: Essays on the tragedies, problem comedies and Shakespeare the man. 2nd edn. Houndmills, Basingstoke [England] : MacMillan Press ; N. Y. : St. Martin’s Press. xii, 253 p. P. $1-3$.

Ocampo-Guzman, A. (2006) My own private Shakespeare, or, Am I deluding myself? // Colorblind Shakespeare: New perspectives on race and performance / ed. by A. Thompson. N. Y. ; L. : Routledge. xvii, 262 p. P. 125-136.

Pogue, K. E. (2006) Shakespeare’s friends. Westport, CT : Praeger. xvii, 183 p.

Rasmus, D. (2016) 'Worlds elsewhere' makes clear: Shakespeare is what we make of him [Электронный pecypc] // PopMatters. June 27. URL: https://popmatters.com/worlds-elsewhere-journeys-around-shakespeares-globe-by-andrew-dickson-2495426794.html [архивировано в WaybackMachine] (дата обращения: 15. 11.2019). 
Roy, P. (2019) "If we ever meet again": The three groups of English Renaissance playwrights // Yearly Shakespeare. Vol. 27. Issue 17. P. 31-38.

Sawyer, R. (2003) Victorian appropriations of Shakespeare: George Eliot, A. C. Swinburne, Robert Browning, and Charles Dickens. Madison, NJ : Fairleigh Dickinson University Press ; L. : Associated University Presses. 172 p.

Tamburlaine the Great - Broadway Play — Original (s.d.) [Электронный pecypc] // IBDB (Internet Broadway Database). URL: https://www.ibdb.com/ broadway-production/tamburlaine-the-great-2397 [архивировано в WaybackMachine] (дата обращения: 15.11.2019).

Дата поступления: 15.11.2019 г.

\section{REFERENCES}

Bioy Casares, A. (s.d.) <Zapis' dnevnika A. Bioia Kasaresa ot 26 iiunia 1957 g. $>$ [<An entry in A. Bioy Casares's diary dated June 26, 1957>]. Prozhito [online] Available at: https://prozhito.org/note/259615 (accessed 15.11.2019). (In Russ.).

Gaydin, B. N. (2018) U. Shekspir v tezauruse Iu. O. Dombrovskogo [W. Shakespeare in Yuri Dombrovsky's Thesaurus]. Gorizonty gumanitarnogo znaniia, no. 4, pp. 27-58. [online] Available at: http://journals.mosgu.ru/ggz/article/view/845 (accessed 19.09.2019). (In Russ.). DOI: 10.17805/ggz.2018.4.3

Gol'd, G. (2017) Ne pei vina, Gertruda [Don't drink wine, Gertrude]. Stikhi.ru, February 7. [online] Available at: https://www.stihi.ru/2017/02/07/3599 [archived in WaybackMachine] (accessed 15.11.2019). (In Russ.).

Dal', O. I. (s.d.) I poshlo, i poekhalo... : <Zapis' dnevnika O. I. Dalia ot 3 aprelia 1975 g.> [One thing led to another... : < An entry in O. I. Dal's diary dated April 3, 1975>] Prozhito. [online] Available at: https://prozhito.org/note/223 $\underline{603}$ (accessed 15.11.2019). (In Russ.).

Dzhivelegov, A. K. (1943) «Universitetskie umy» [“University Wits”]. In: Istoriia angliiskoi literatury [History of English literature] : in 3 vols. Moscow ; Leningrad : Publ. House of the Academy of Sciences of the USSR. Vol. 1, issue 1. Pp. 341-361. (In Russ.).

Dostoevsky, F. M. (1978) G-n —bov i vopros ob iskusstve [Mr. —bov and the question of art]. In: Dostoevsky, F. M. Polnoe sobranie sochinenii [Complete works] : in 30 vols. Leningrad : Nauka Publ., Leningrad Branch. Vol. 18: Stat'i i zametki. 1845-1861 [Articles and notes. 1845-1861]. 371 p. Pp. 70-103. (In Russ.).

Zhukovsky, V. A. (2004) Zhurnal, [1805-1806] [Journal, [1805-1806]]. In: Zhukovsky, V. A. Polnoe sobranie sochinenii i pisem [Complete works and letters] : in 20 vols. Moscow : Iazyki slavianskoi kul'tury Publ. Vol. 13: Dnevniki. Pis'ma-dnevniki. Zapisnye knizhki. 1804-1833 gg. [Diaries. Letters-diaries. Note- 
books. 1804-1833] / comp. and ed. by O. B. Lebedev, A. S. Ianushkevich. 608 p. Pp. 13-37. (In Russ.).

Zhukovsky, V. A. (s.d.) <Zapis' dnevnika V. A. Zhukovskogo ot 1806 g.> [ $<$ An entry in V. A. Zhukovsky's diary dated 1806>]. Prozhito [online] Available at: https://prozhito.org/note/180718 (accessed 15.11.2019). (In Russ.).

Zakharov, N. V. (2008) Shekspirizm russkoi klassicheskoi literatury: tezaurusnyi analiz [Shakespearianism of Russian classical literature: The thesaurus analysis] / ed. by Vl. A. Lukov ; Moscow University for the Humanities. The Institute of Fundamental Applied Studies; The International Academy of Science. Moscow : Moscow University for the Humanities Publ. 320 p. (In Russ.).

Zakharov, N. V. (2010) Retseptsiia Shekspira v tvorchestve Zhukovskogo [The reception of Shakespeare in V. A. Zhukovsky's creative works]. Znanie. Ponimanie. Umenie, no. 1, pp. 104-108. (In Russ.).

Kazakevich, E. G. (s.d.) Metaiushchii kop'e: opyt literaturnoi kharakteristiki V. Shekspira : <Zapis' dnevnika E. G. Kazakevicha ot 1 ianvaria 1953 g.> [Flingspear: An experience of literary assessment of W. Shakespeare : <An entry in E. G. Kazakevich's diary dated January 1, 1953>]. Prozhito [online] Available at: https://prozhito.org/note/245811 (accessed 15.11.2019). (In Russ.).

Kuzmin, M. A. (1998) Dnevnik 1934 goda [Diary of 1934] / comp., text preparation, opening chapter, comm. by G. A. Morev. St. Petersburg : Ivan Limbakh Publishing House. 416 p. (In Russ.).

Kuzmin, M. A. (s.d.) <Zapis' dnevnika M. A. Kuzmina ot 23-26 oktiabria 1934 g.> [<An entry in M. A. Kuzmin's diary dated October 23-26, 1934>]. Prozhito [online] Available at: https://prozhito.org/note/545148 (accessed 15.11. 2019). (In Russ.).

Larskaia, G. G. (s.d.) <Zapis' dnevnika G. G. Larskoi ot 23 aprelia 2017 g.> [<An entry in G. G. Larskaia's diary dated April 23, 2017>]. Prozhito [online] Available at: https://prozhito.org/note/365012 (accessed 15.11.2019). (In Russ.).

Lebedeva, O. B. and Ianushkevich, A. S. (2016) Otryvki iz pisem o Saksonii (primechaniia) [Extracts from letters on Saxony (Notes)]. In: Zhukovsky, V. A. Polnoe sobranie sochinenii i pisem [Complete works and letters] : in 20 vols. Moscow : "IaSK” Publ. House. Vol. 11 (1st half of the volume): Proza 1810-1840kh godov [Prose of the 1810s-1840s] / ed. by A. S. Ianushkevich. 1048 p. Pp. 649657. (In Russ.).

Lukov, V. A. and Lukov, Vl. A. (2008) Tezaurusy: Sub"ektnaia organizatsiia gumanitarnogo znaniia [Thesauri: The subjective organization of humanities knowledge]. Moscow : The National Institute of Business Publ. 784 p. (In Russ.).

Lukov, V. A. and Lukov, Vl. A. (2013) Tezaurusy II: Tezaurusnyi podkhod $k$ ponimaniiu cheloveka i ego mira [Thesauri II: The thesaurus approach to the 
conceptualization of the person and his/her world]. Moscow : The National Institute of Business Publ. 640 p. (In Russ.).

Lukov, Vl. A. (2010-) Angliiskaia renessansnaia dramaturgiia «universitetskikh umov» - predshestvennikov Shekspira [English Renaissance drama of the "university wits" - Shakespeare's predecessors]. Entsiklopediia «Mir Shekspira» [An Electronic Encyclopaedia "The World of Shakespeare"] [online] Available at: http://www.world-shake.ru/ru/Encyclopaedia/4136.html [archived in WaybackMachine] (accessed 15.11.2019). (In Russ.).

Lukov, Vl. A. and Zakharov, N. V. (2008) Shekspirizatsiia i shekspirizm [Shakespearisation and Shakespearianism]. Znanie. Ponimanie. Umenie, no. 3, pp. 253-256. (In Russ.).

Marlowe, C. (1961) Sochineniia [Works]. Moscow : Gosudarstvennoe izdatel'stvo khudozhestvennoi literatury [State Publishing House of Fiction Literature]. 662 p. (In Russ.).

Morozova (Tsyrlina), L. (2010) Durachit'sia, ot nezhnosti spasaias' [To play the fool pulling through tenderness]. Stikhi.ru, June 16. [online] Available at: https://www.stihi.ru/2010/06/16/553 [archived in WaybackMachine] (accessed 15.11.2019). (In Russ.).

Nazirov, R. G. (s.d.) <Zapis' dnevnika R. G. Nazirova ot 6 dekabria 1957 g. $>$ [<An entry in R. G. Nazirov's diary dated December 6, 1957>]. Prozhito [online] Available at: https://prozhito.org/note/182195 (accessed 15.11.2019). (In Russ.).

Popov, K. S. (s.d.) <Zapis' dnevnika K. S. Popova ot 14 fevralia 1930 g.> [<An entry in K. S. Popov's diary dated February 14, 1930>]. Prozhito [online] Available at: https://prozhito.org/note/312307 (accessed 15.11.2019). (In Russ.).

$<$ Rezul'taty po kliuchevomu slovu «Marlo» $>[<$ Results for keyword "Marlo" >] (s.d.) Prozhito [online] Available at: https://prozhito.org/notes?keywords =["Марло"] (accessed 15.11.2019). (In Russ.).

$<$ Rezul'taty po kliuchevomu slovu «Marlou» $>$ [ $<$ Results for keyword "Marlou" $>$ ] (s.d.) Prozhito [online] Available at: https://prozhito.org/notes?keywords= ["Марлоу"] (accessed 15.11.2019). (In Russ.).

$<$ Rezul'taty po kliuchevomu slovu «Shekspir»> [ $<$ Results for keyword "Shekspir" >] (s.d.) Prozhito [online] Available at: https://prozhito.org/notes? keywords=["Шекспир"] (accessed 15.11.2019). (In Russ.).

Sakharov, A. D. (1996) Vospominaniia [Memoirs] : in 2 vols. / compiling editors: E. Kholmogorova, Yu. Shikhanovich. Moscow : Prava cheloveka Publ. Vol. 1. 912 p. (In Russ.).

Sakharov, A. D. (s.d.) <Zapis' dnevnika A. D. Sakharova 6-7 fevralia 1980 g. $>$ [<An entry in A. D. Sakharov's diary dated February 6-7, 1980>]. Prozhito 
[online] Available at: https://prozhito.org/note/430982 (accessed 15.11.2019). (In Russ.).

Sakharov, A. D. and Bonner, E. G. (2006) Dnevniki. Roman-dokument [Diaries. A novel-document] : in 3 vols. Moscow : Vremia Publ. Vol. 2. 864 p. (In Russ.).

Troitskii, N. (2018) Dnevnik. Glava 4. Chitatel'skii pir dukha [Diary. Chapter 4. Reader's feast of spirit]. Nikolai Troitskii - ZhZh [Nikolai Troitskii's LiveJournal], December 13. [online] Available at: https://nicolaitroitsky.livejournal.com/8231100.html [archived in WaybackMachine] (accessed 15.11.2019). (In Russ.).

Troitskii, N. Ya. (s.d.) <Zapis' dnevnika N. Ya. Troitskogo ot 21 dekabria 1982 g.> [<An entry in N. Ya. Troitskii’s diary dated December 21, 1982>]. Prozhito [online] Available at: https://prozhito.org/note/128624 (accessed 15.11. 2019). (In Russ.).

U. Shekspir, ego proizvedeniia i geroi na karte Rossii [W. Shakespeare, his works and characters on the map of Russia]. Informatsionno-issledovatel'skaia baza dannykh "Russkii Shekspir" [Information and research database "Russian Shakespeare"] [online] Available at: http://rus-shake.ru/menu/Shakespeare-map/ (accessed 15.11.2019). (In Russ.).

Shvarts, E. A. (s.d.) <Zapis' dnevnika E. A. Shvarts ot 8 sentiabria 1963 g.> [ $<$ An entry in E. A. Shvarts's diary dated September 8, 1963>]. Prozhito [online] Available at: https://prozhito.org/note/105121 (accessed 15.11.2019). (In Russ.).

Shevyrev, S. P. (1853) O znachenii Zhukovskogo v russkoi zhizni i poezii : rech', proiznesennaia $v$ torzhestvennom sobranii Moskovskogo universiteta ordinarnym professorom russkoi slovesnosti Stepanom Shevyrevym 12 ianvaria 1853 g. [On the significance of Zhukovsky in Russian life and poetry: A speech delivered at the solemn meeting of Moscow University by the full professor of literature Stepan Shevyrev on January 12, 1853]. Moscow : Universitetskaia tipografiia [University Printing House]. [4], 84, 16, 25 p. (In Russ.).

Callwood, J. (1956) How Stratford went to Broadway. MacLean's Magazine, March 3, pp. 8-11, 50-53. [online] Available at: https://archive. macleans.ca/article/1956/3/3/how-stratford-went-to-broadway [archived in WaybackMachine] (accessed 15.11.2019). (In Russ.).

Deathwatch (2002) (s.d.) Rotten Tomatoes [online] Available at: https:// www.rottentomatoes.com/m/deathwatch [archived in WaybackMachine] (accessed 15.11.2019).

Dobson, M. (2011) Shakespeare in private: Domestic performance. In: Dobson, M. Shakespeare and amateur performance: A cultural history. Cambridge ; N. Y. : Cambridge University Press. xiii, 265 p. Pp. 22-64. DOI: 10.1017/ $\underline{\text { CBO9780511801259.002 }}$ 
Goodman, A. (1997) Virtuous philosopher and chameleon poet: The Shakespeare of Samuel Johnson and John Keats : Diss. Stanford, CA : Stanford University. viii, 236 leaves.

Honigmann, E. A. J. (1998) Introduction: Myriad-minded Shakespeare and the modern reader. In: Honigmann E. A. J. Myriad-minded Shakespeare: Essays on the tragedies, problem comedies and Shakespeare the man. 2nd edn. Houndmills, Basingstoke [England] : MacMillan Press ; N. Y. : St. Martin's Press. xii, 253 p. Pp. 1-3.

Ocampo-Guzman, A. (2006) My own private Shakespeare, or, Am I deluding myself? In: Colorblind Shakespeare: New perspectives on race and performance / ed. by A. Thompson. N. Y. ; L. : Routledge. xvii, 262 p. Pp. 125-136.

Pogue, K. E. (2006) Shakespeare's friends. Westport, CT : Praeger. xvii, $183 \mathrm{p}$.

Rasmus, D. (2016) 'Worlds elsewhere' makes clear: Shakespeare is what we make of him. PopMatters, June 27. [online] Available at: https:// popmatters.com/worlds-elsewhere-journeys-around-shakespeares-globe-by-andrew -dickson-2495426794.html [archived in WaybackMachine] (accessed 15.11.2019).

Roy, P. (2019) "If we ever meet again": The three groups of English Renaissance playwrights. Yearly Shakespeare, vol. 27, issue 17, pp. 31-38.

Sawyer, R. (2003) Victorian appropriations of Shakespeare: George Eliot, A. C. Swinburne, Robert Browning, and Charles Dickens. Madison, NJ : Fairleigh Dickinson University Press ; L. : Associated University Presses. 172 p.

Tamburlaine the Great - Broadway Play — Original (s.d.) IBDB (Internet Broadway Database) [online] Available at: https://www.ibdb.com/broadwayproduction/tamburlaine-the-great-2397 [archived in WaybackMachine] (accessed 15.11.2019).

Submission date: 15.11.2019.

Гайдин Борис Николаевич - кандидат философских наук, начальник научно-исследовательского отдела цифровых технологий Института фундаментальных и прикладных исследований Московского гуманитарного университета, член-корреспондент Международной академии наук (IAS, Инсбрук). Адрес: 111395, Россия, г. Москва, ул. Юности, 5, корп. 6. Тел.: +7 (499) 374-59-30. Эл. адрес: bngaydin@mosgu.ru 
Gaydin Boris Nikolaevich, Candidate of Philosophy, Head of the Research Department of Digital Technologies, Institute of Fundamental and Applied Studies, Moscow University for the Humanities; Associate Member, International Academy of Science (IAS, Innsbruck). Postal address: Bldg. 6, 5 Yunosti St., Moscow, Russian Federation, 111395. Tel.: +7 (499) 374-59-30. E-mail: bngaydin@mosgu. $\underline{\mathrm{ru}}$

\section{Для изитирования:}

Гайдин Б. Н. У. Шекспир и К. Марло в индивидуальных тезаурусах (на материале русскоязычных дневников XIX-XXI вв.) [Электронный ресурс] // Горизонты гуманитарного знания. 2019. № 6. C. 43-59. URL: http:// journals.mosgu.ru/ggz/article/view/1091 (дата обращения: дд.мм.гггг). DOI: 10. 17805/ggz.2019.6.3 